\title{
PROFUNDIDADE DE SEMEADURA E CARGA APLICADA NA RODA COMPACTADORA PARA PRODUÇÃO DE MILHO SILAGEM
}

Jorge Wilson Cortez ${ }^{1}$, Pamela José Alves ${ }^{2}$, Danilo César Checchio Grotta ${ }^{3}$, Carlos Eduardo Angeli Furlani ${ }^{4}$, Rouverson Pereira da Silva ${ }^{4}$

\section{RESUMO}

Objetivou-se, com o presente trabalho, avaliar os efeitos da profundidade de deposição das sementes e das cargas verticais sobre a roda compactadora, nos atributos físicos do solo e agronômicos do milho. O ensaio foi realizado no campus da UNESP de Jaboticabal com o delineamento inteiramente casualizado no esquema fatorial 4 x 3 , sendo comparadas quatro cargas verticais $(62,7 ; 160,7 ; 258,7$ e $356,7 \mathrm{~N})$ e três profundidades de semeadura $(0,03 ; 0,05$ e $0,07 \mathrm{~m})$ com três repetições. As variáveis analisadas foram: número de dias para a emergência das plântulas, resistência do solo à penetração, perdas de massa na colheita, umidade massas verde e seca das plantas de milho. Os resultados evidenciaram que à resistência do solo à penetração foi afetada após a passagem das rodas compactadoras pelas diferentes cargas verticais. Não houve efeito dos fatores sobre o número de dias para a emergência, assim como as produções de matéria seca e verde e as perdas no processo de trituração da biomassa de milho.

Palavras-chave: massa seca, resistência do solo à penetração, mecanização agrícola.

\section{SEEDING DEPTH AND VERTICAL LOAD ON PRESS WHEELS FOR CULTIVATION OF SILAGE CORN}

\begin{abstract}
This study was done to evaluate the influence of sowing depth and vertical load on the press wheel on the physical characteristics of soil and agronomic characteristics of corn. The experiment was done in the completely randomized design with four vertical load $(62.7 ; 160.7 ; 258.7$ or $356.7 \mathrm{~N})$, three sowing depths $(0.03 ; 0.05$ or $0.07 \mathrm{~m})$, with three replications. Following variable were evaluated: resistance to soil penetration, losses at harvest, number of days for plant emergence, and fresh and dry matter yield. The resistance to penetration was affected by different loads on the press wheels. There was no effect on the number of days to plant emergence, dry and fresh matter production, and losses during triturating processes.
\end{abstract}

Keywords: dry matter, soil penetration resistance, agricultural mechanization.

\section{Recebido para publicação em 31/08/2009. Aprovado em 19/03/2010.}

1- Eng. Agrônomo, Prof. Adjunto da Universidade Federal do Vale do São Francisco - UNIVASF. jorge.cortez@univasf.edu.br

2-Zootecnista, Mestre em Agronomia (Produção Vegetal) UNESP - Jaboticabal, Departamento de Engenharia Rural. pamjalves@yahoo.com.br

3- Eng. Agrônomo, Prof Dr, UNIFEB, Barretos, SP. dcgrotta@yahoo.com.br

4- Prof. Dr. Departamento de Engenharia Rural, Faculdade de Ciências Agrárias e Veterinárias, Universidade Estadual Paulista. Bolsista de Produtividade do CNPq. furlani@,fcav.unesp.br, rouverson@,fcav.unesp.br 


\section{INTRODUÇÃO}

A temperatura, umidade e o tipo de solo são fatores que condicionam a profundidade de semeadura. $\mathrm{O}$ fato de a semente ser colocada em diferentes profundidades não interfere na profundidade do sistema radicular definitivo (FANCELLI \& DOURADO NETO, 2000).

A semeadura deve ser mais superficial,na faixa de 0,03 a $0,05 \mathrm{~m}$ em solos mais argilosos, que dificultam a emergência, ou quando a temperatura do solo é mais fria, em função da época ou da região; em solos mais leves, arenosos, a profundidade pode ser maior, variando de 0,03 a $0,08 \mathrm{~m}$, aproveitando as condições mais favoráveis de umidade do solo (FORNASIERI FILHO, 2007). A germinação das sementes, uma das etapas primordiais para a implantação dos cultivos comerciais, é uma das responsáveis pelo estabelecimento da população desejada e, conseqüentemente, pelo rendimento final da lavoura de milho (VIANA et al., 2005).

Ritchie et al. (2003) constataram que para a germinação e emergência mais rápidas, a semeadura superficial se beneficia das temperaturas do solo mais favoráveis próximo da superfície, já as maiores profundidades de semeadura geralmente proporcionam maior umidade para as sementes, mais dificultam a emergência.

Trabalhos que tratam dos efeitos da compressão do solo no leito de semeadura, na emergência e no crescimento das plantas, são contraditórios e revelam tanto efeitos positivos (SORDI, 2000), quanto negativos em relação ao vigor inicial da lavoura (CORTEZ et al., 2006a).

Silva et al. (2005) observaram que a aplicação de cargas estáticas no intervalo de 75 a $325 \mathrm{~N}$ provocou elevação central do solo na linha de semeadura, para as cargas acima de $325 \mathrm{~N}$, observaram tendência de redução da elevação central, com ocorrência de compactação direta sobre a linha de semeadura.

Furlani et al. (2001) não encontraram diferenças significativas no número médio de dias para emergência de plântulas de milho quando utilizadas diferentes cargas e profundidades de semeadura. Os autores demonstraram que a resistência do solo à penetração aumentou em com o incremento das cargas e profundidades.

Segundo Silva (2002) o efeito de rodas compactadoras submetidas a cargas verticais e profundidades de semeadura nas características agronômicas do milho observou que a profundidade de semeadura é, dentre os fatores estudados, o que mais influencia a emergência e o desenvolvimento vegetativo da cultura do milho. $\mathrm{O}$ autor ainda afirma que as sementes depositadas à profundidade de $0,03 \mathrm{~m}$, necessitam de menor número de dias para emergência, e apresentam maior porcentagem de emergência do que aquelas colocadas em profundidades de 0,05 e $0,07 \mathrm{~m}$.

Objetivou-se, no presente trabalho, avaliar os efeitos da profundidade de deposição de sementes e das cargas verticais sobre a roda compactadora, sobre as características físicas do solo e agronômicas do milho.

\section{MATERIAL E MÉTODOS}

O experimento foi conduzido na área experimental do Departamento de Engenharia Rural da UNESP Jaboticabal, situada nas coordenadas geodésicas de Latitude $21^{\circ} 15^{\prime} \mathrm{S}$ e Longitude $48^{\circ} 18^{\prime} \mathrm{W}$, com altitude de $559 \mathrm{~m}$, em março de 2006.

O clima da região é classificado, segundo Köeppen (1948), como mesotérmico com inverno seco (Aw) e com chuvas de verão. O solo da área experimental é classificado como Latossolo Vermelho Eutroférrico típico, A moderado, textura argilosa e relevo suave ondulado (EMBRAPA, 2006).

O delineamento adotado foi inteiramente casualizado em esquema fatorial $4 \times 3$, com quatro cargas $(62,7 ; 160,7 ; 258,7$ e $356,7 \mathrm{~N})$ e três profundidades de semeadura $(0,03 ; 0,05$ e $0,07 \mathrm{~m})$, com 3 repetições, resultando em 36 parcelas.

A área experimental foi constituída de duas faixas de solo delimitadas por trilhos, dispostas no sentido leste-oeste, cada uma com 1,5 m de largura por $22,0 \mathrm{~m}$ de comprimento, sendo as parcelas de $1,5 \mathrm{~m} \times 2,5 \mathrm{~m}\left(3,8 \mathrm{~m}^{2}\right)$ que apresentavam intervalos de 1,0 m. Sobre os trilhos desloca-se trole elétrico, com velocidade constante de $0,37 \mathrm{~m} \mathrm{~s}^{-1}$, no qual é possível acoplar acessórios como: plaina niveladora, sulcador, roda compactadora e equipamentos para irrigação; permitindo o desenvolvimento de ensaios com boa precisão.

O preparo do solo foi realizado a $0,15 \mathrm{~m}$ de profundidade com enxada rotativa utilizando, faca tipo veloz tracionado por um trator de rabiças da marca TOBATTA, com potência de 9,42 kW (12 cv), modelo 90, quando o solo se encontrava na condição friável, com regulagens que resultam agregados pequenos. No dia da semeadura, o solo foi nivelado com uma plaina niveladora acoplada ao trole com o 
solo na capacidade friável. Foi realizado o sorteio das parcelas, posteriormente com auxílio de um sulcador acoplado ao trole, foram abertos sulcos no solo de $0,90 \mathrm{~m}$ (espaçamento da cultura), nas três profundidades: 0,$03 ; 0,05$ e $0,07 \mathrm{~m}$. Nos sulcos foram colocadas, manualmente, sementes do cultivar AG 1051 distanciadas de $0,13 \mathrm{~m}$ entre si $(7,6$ sementes $\mathrm{m}^{-1}$ ). Os sulcos foram cobertos com o auxílio de uma régua de madeira. Após o fechamento dos sulcos foi realizada a compactação do solo sobre as sementes, utilizando-se de uma roda compactadora de alumínio, de superfície plana, acoplada ao trole, com largura de $0,10 \mathrm{~m}$ e $0,40 \mathrm{~m}$ de diâmetro. Para se obter as cargas verticais de 62,$7 ; 160,7 ; 258,7$ e $356,7 \mathrm{~N}$ foram utilizados lastros metálicos de $0 ; 10$; 20 e $30 \mathrm{~kg}$ sobre a plataforma suporte.

A adubação de semeadura (com base na análise química do solo) foi de $350 \mathrm{~kg} \mathrm{ha}^{-1}$, da formulação 4-14-8 (N-P-K). A irrigação foi utilizada com base nos dados de uma estação metereológica instalada ao lado da área de estudo. A adubação de cobertura foi efetuada 25 dias após a semeadura, com $300 \mathrm{~kg}$ ha $^{-1}$ de sulfato de amônio $\left[\left(\mathrm{NH}_{4}\right)_{2} \mathrm{SO}_{4}\right]$. O controle de plantas daninhas foi realizado por meio de capinas manuais. O controle da lagarta do cartucho (Spodoptera frugiperda) foi realizado aos 28 dias após a semeadura, com a aplicação do inseticida lufenurom, com pulverizador costal, na dose de 0,3 $\mathrm{L} \mathrm{ha}^{-1}$ e volume de calda de $200 \mathrm{~L} \mathrm{ha}^{-1}$.

Para o cálculo do número médio de dias para a emergência das plântulas (Equação 1) foram realizadas contagens nos 10 primeiros dias após a semeadura, sendo considerada emergida a plântula que pudesse ser visualizada sobre a superfície do solo, conforme especificado por Edmond \& Drapalla (1958).

$M=\frac{\left[\left(\mathrm{N}_{1} \cdot \mathrm{G}_{1}\right)+\left(\mathrm{N}_{2} \cdot \mathrm{G}_{2}\right)+\ldots+(\mathrm{Nn} \cdot \mathrm{Gn})\right]}{\left(\mathrm{G}_{1}+\mathrm{G}_{2}+\cdots+\mathrm{Gn}\right)}$

em que,

$\mathrm{M}=$ número médio de dias para a emergência das plântulas;

$\mathrm{N}_{1}=$ número de dias entre a semeadura e a primeira contagem de plântulas;

$\mathrm{G}_{1}=$ número de plântulas emergidas na primeira contagem;

$\mathrm{N}_{2}=$ número de dias entre a semeadura e a segunda contagem de plântulas;

$\mathrm{G}_{2}=$ número de plântulas emergidas entre a primeira e a segunda contagem;
$\mathrm{N}_{\mathrm{n}}=$ número de dias entre a semeadura e a última contagem de plântulas, $\mathrm{e}$

$\mathrm{G}_{\mathrm{n}}=$ número de plântulas emergidas entre a penúltima e a última contagem.

Para a análise da resistência do solo à penetração, após a semeadura, foi utilizado um mini-penetrômetro, que se caracteriza por possibilitar a realização de medidas em diversas profundidades sem causar grandes alterações no solo. Foram realizadas duas medições por parcela, uma a $0,05 \mathrm{~m}$ e outra a $0,10 \mathrm{~m}$ de profundidade, ao longo da área onde a roda compactadora passou. A partir das leituras do mini-penetrômetro calculouse a resistência do solo à penetração por meio da equação 2 .

$\mathrm{Rp}=\mathrm{LK}$

em que,

$\mathrm{Rp}=$ resistência do solo à penetração, $\mathrm{MPa}$,

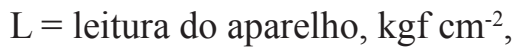

$\mathrm{K}$ = fator unitário de conversão, 0,1023.

Para determinar o teor de água no solo, no momento da coleta da resistência a penetração, foram retiradas amostras na área (10 amostras), na camada de até $-0,1 \mathrm{~m}$, após a passagem da roda compactadora.

A massa verde e seca da parte aérea foram obtidas com a colheita de 10 plantas por parcela, no momento do ponto de silagem e pesadas na seqüência. Depois de trituradas em triturador estacionário, marca Penha, composto de quatro facas acionadas por um motor de $2,57 \mathrm{~kW}(3,5$ cv) a $3500 \mathrm{rpm}$, obteve-se a massa de material triturado (massa verde), que foi levado à estufa elétrica de ventilação forçada a $60{ }^{\circ} \mathrm{C}$ por $72 \mathrm{~h}$ (EMBRAPA, 1999), obtendo-se assim a massa seca por meio de nova pesagem.

A umidade da biomassa de milho foi determinada pela diferença de peso entre as plantas úmidas e secas. A diferença entre as massas de plantas antes e depois de trilhadas foi considerado como as perdas no processo mecânico.

Os dados foram submetidos a análise de variância a $5 \%$ de probabilidade e aplicouse teste de Tukey para comparação de médias. Quando a interação entre fatores foi significativa os resultados foram apresentados na forma de superfície de resposta. 


\section{RESULTADOS E DISCUSSÃO}

No Quadro 1 é apresentado o número de dias para emergência (NDE) da cultura do milho. Observa-se que tanto o fator carga vertical como as profundidades de semeadura não influenciaram o $\operatorname{NDE}(\mathrm{P}>0,05)$. Furlani et al. (2001) que estudaram a cultura do milho nas mesmas profundidades de semeadura e com cargas similares, concluíram que os resultados diferiram quanto ao NDE, sendo de 4,2.

Cortez et al. (2007) não encontraram diferença no
NDE em função do modelo da roda compactadora e a carga vertical $(0,100$ e $200 \mathrm{~N})$ na hora de semeadura do milho. Pelos resultados, desde que o solo esteja com alta umidade, os fatores cargas verticais e profundidades de semeadura pouco afetam a emergência das plântulas.

A resistência do solo à penetração $(\mathrm{RP})$ após a passagem das rodas compactadoras variou com as cargas verticais impostas e foram diferentes $(\mathrm{P} \leq 0,05)$ nas duas camadas estudadas (Quadro 1). A umidade no momento da coleta da resistência do solo à penetração foi de $25 \%$.

Quadro 1. Número de dias para emergência (NDE) e resistência do solo à penetração (RP) após a passagem da roda compactadora

\begin{tabular}{cccc}
\hline & NDE & \multicolumn{2}{c}{$\mathrm{RP}(\mathrm{MPa})$} \\
\cline { 3 - 4 } Fatores & & $0,0-0,05(\mathrm{~m})$ & $0,05-0,10(\mathrm{~m})$ \\
\hline Cargas $(\mathrm{N})$ & $8,3 \mathrm{a}$ & $0,11 \mathrm{~b}$ & $0,33 \mathrm{~b}$ \\
62,7 & $8,1 \mathrm{a}$ & $0,13 \mathrm{ab}$ & $0,42 \mathrm{ab}$ \\
160,7 & $8,5 \mathrm{a}$ & $0,18 \mathrm{ab}$ & $0,41 \mathrm{ab}$ \\
258,7 & $7,8 \mathrm{a}$ & $0,22 \mathrm{a}$ & $0,44 \mathrm{a}$ \\
356,7 & & & \\
Prof. (m) & $9,3 \mathrm{a}$ & $0,25 \mathrm{a}$ & $0,41 \mathrm{a}$ \\
0,03 & $7,9 \mathrm{a}$ & $0,13 \mathrm{~b}$ & $0,37 \mathrm{a}$ \\
0,05 & $7,4 \mathrm{a}$ & $0,10 \mathrm{~b}$ & $0,42 \mathrm{a}$ \\
0,07 & & & $3,56^{*}$ \\
Teste F & $0,2^{\mathrm{NS}}$ & $3,50 *$ & $1,76^{\mathrm{NS}}$ \\
Cargas (C) & $3,0^{\mathrm{NS}}$ & $12,13 * *$ & $0,62^{\mathrm{NS}}$ \\
Prof. (P) & $1,7^{\mathrm{NS}}$ & $0,76^{\mathrm{NS}}$ & 17,9 \\
C x P & 23,5 & 50,1 & .
\end{tabular}

Médias seguidas de mesmas letras minúsculas na coluna não diferem entre si pelo teste de Tukey a $5 \%$ de probabilidade Ns: não significativo $(\mathrm{P}>0,05)$; *: significativo $(\mathrm{P} \leq 0,05)$; **; significativo $(\mathrm{P} \leq 0,01), \mathrm{C} . \mathrm{V}$.: coeficiente de variação.

Quadro 2. Análise de variância para perdas (P), umidade da biomassa (U) e produtividade de massa verde (Mv) e seca (Ms)

\begin{tabular}{ccccc}
\hline Fatores & $\mathrm{P}(\%)$ & $\mathrm{U}(\%)$ & $\mathrm{Mv}\left(\mathrm{kg} \mathrm{ha}^{-1}\right)$ & $\mathrm{Ms}\left(\mathrm{kg} \mathrm{ha}^{-1}\right)$ \\
\hline Cargas $(\mathrm{N})$ & & & \\
\hline 62,7 & $6,9 \mathrm{a}$ & $71,9 \mathrm{a}$ & $53.100 \mathrm{a}$ & $4.300 \mathrm{a}$ \\
160,7 & $7,3 \mathrm{a}$ & $71,7 \mathrm{a}$ & $58.200 \mathrm{a}$ & $4.000 \mathrm{a}$ \\
258,7 & $7,2 \mathrm{a}$ & $72,8 \mathrm{a}$ & $54.300 \mathrm{a}$ & $4.800 \mathrm{a}$ \\
356,7 & $7,5 \mathrm{a}$ & $72,4 \mathrm{a}$ & $58.900 \mathrm{a}$ & $4.600 \mathrm{a}$ \\
\hline Prof. (m) & & & \\
\hline 0,03 & $6,9 \mathrm{a}$ & $72,9 \mathrm{a}$ & $54.400 \mathrm{a}$ & $4.700 \mathrm{a}$ \\
0,05 & $7,1 \mathrm{a}$ & $71,8 \mathrm{a}$ & $59.500 \mathrm{a}$ & $4.600 \mathrm{a}$ \\
0,07 & $7,7 \mathrm{a}$ & $71,9 \mathrm{a}$ & $54.400 \mathrm{a}$ & $4.000 \mathrm{a}$ \\
\hline Teste F & & & \\
\hline Cargas (C) & $0,04^{\mathrm{NS}}$ & $1,04^{\mathrm{NS}}$ & $0,50^{\mathrm{NS}}$ & $1,46^{\mathrm{NS}}$ \\
Prof. (P) & $0,13^{\mathrm{NS}}$ & $1,90^{\mathrm{NS}}$ & $0,73 \mathrm{NS}^{\mathrm{NS}}$ & $2,26^{\mathrm{NS}}$ \\
C x P & $0,80^{\mathrm{NS}}$ & $3,48^{*}$ & $0,46^{\mathrm{NS}}$ & $0,97^{\mathrm{NS}}$ \\
\hline C.V. (\%) & 57,75 & 2,07 & 21,43 & 19,07 \\
\hline
\end{tabular}

Em cada coluna, para cada fator, médias seguidas de mesmas letras minúsculas não diferem entre si pelo Teste de Tukey a $5 \%$ de probabilidade. ${ }^{\text {NS: }}$ não significativo $(\mathrm{P}>0,05)$; *: significativo $(\mathrm{P} \leq 0,05)$; ${ }^{* *}$; significativo $(\mathrm{P} \leq 0,01), \mathrm{C} . \mathrm{V}$.: coeficiente de variação. 
Na camada de 0,0-0,05 m, a RP variou em função da profundidade $(\mathrm{P} \leq 0,01)$ e das cargas verticais $(\mathrm{P} \leq 0,05)$, $\mathrm{e}$ observa-se que o aumento das cargas verticais ocasionou aumento da RP (Figura 1a), sendo na maior carga observada a maior resistência, embora não diferindo estatisticamente das cargas 258,7 e 160,7 N. A menor profundidade apresentou a maior RP, provavelmente por esta ter mobilizado menor quantidade de solo, toda a carga aplicada a ela se concentrou na parte superior (Figura 1b).

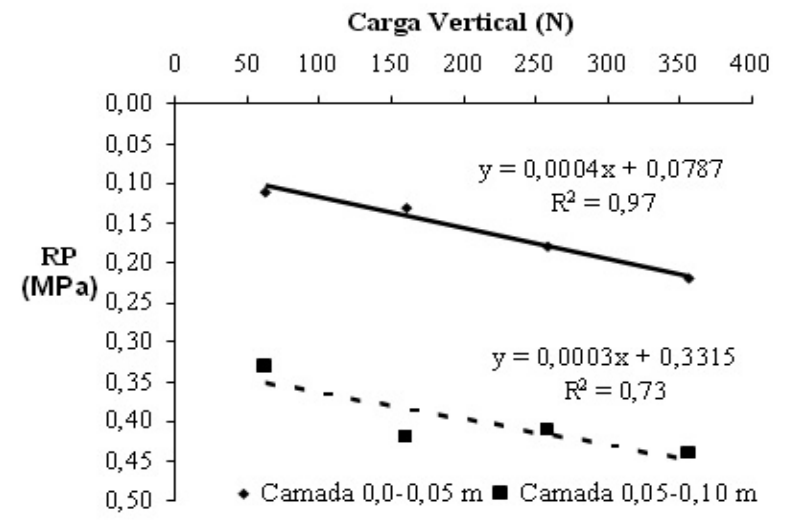

b

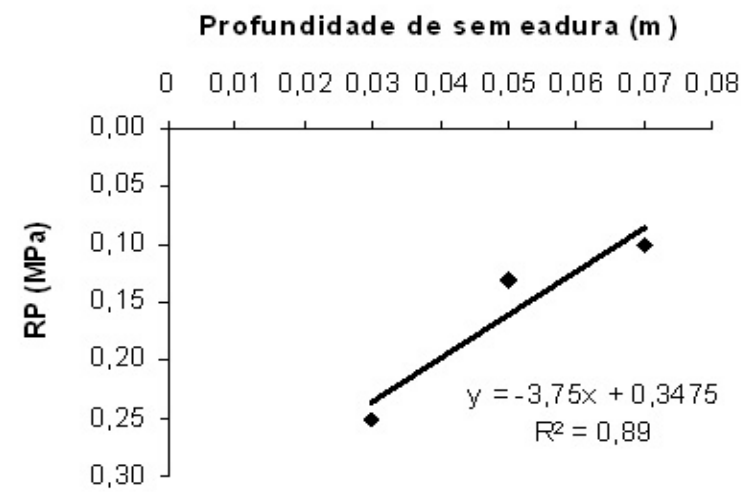

Figura 1. Análise de regressão para a resistência do solo à penetração $(\mathrm{MPa})$ nas profundidades de 0,05 e $0,10 \mathrm{~m}$ em função das cargas verticais aplicadas (A) e na profundidade de $0,05 \mathrm{~m}$ em função da profundidade de semeadura (B).
$\mathrm{Na}$ camada de 0,05-0,10 $\mathrm{m}$ apenas o fator carga exerceu efeito significativo sobre a $\mathrm{RP}(\mathrm{P} \leq 0,05)$. A menor carga, na qual havia apenas o peso da roda compactadora, diferiu da maior carga, e as cargas intermediárias não diferiram entre si (Quadro 1). Observa-se o efeito linear do aumento da carga com o aumento da resistência do solo à penetração (Figura 1a). Caso o aumento da carga na roda compactadora fosse maior, poderia ocorrer da RP se tornar constante.

Pelo exposto, fica evidenciado que a compactação na superfície do solo na região da semente alterou a resistência do solo à penetração, concordando com Johnson \& Bichele (1961). Outra observação feita é que as maiores cargas proporcionam maiores resistências do solo à penetração, (FURLANI et al., 2001).

As perdas da biomassa vegetal do milho (Quadro 2) apresentaram valor médio de 7,24\% ( $>>0,05)$, e as mesmas podem ser consideradas como de água no corte pela máquina, como a perda de biomassa vegetal, seja pelo vento ou resíduos que ficaram no interior da máquina.

A umidade (Quadro 2) da biomassa de milho não foi afetada pelos fatores independentemente $(\mathrm{P}>0,05)$, isso fez com que resultasse em grande quantidade de massa verde $(\mathrm{P}>0,05)$ e pequena quantidade de massa seca $(\mathrm{P}>0,05)$. A umidade da biomassa de milho apresentou ação conjunta dos fatores testados $(\mathrm{P} \leq 0,05)$, sendo as médias apresentadas no Quadro 3 e a análise de regressão na Figura 2.

Para a massa seca do milho, Silva (2002) ao trabalhar com cargas verticais $(50,100$ e $150 \mathrm{~N})$ e profundidades de semeadura do milho $(0,03 ; 0,05$ e $0,07 \mathrm{~m})$, avaliou aos vinte e um dias após a emergência e não encontrou diferença para estes fatores. Estes dados concordam com os relatos de Cortez et al., (2007) que ao trabalharem com avaliação de cargas verticais $(0,100$ e $200 \mathrm{~N})$ encontraram produção média de $9.050 \mathrm{~kg} \mathrm{ha}^{-1}$ de matéria seca ao final do ciclo da cultura do milho.

Analisando a umidade da biomassa de milho nas profundidades dentro das cargas (Quadro 3), observase que apenas a profundidade de $0,05 \mathrm{~m}$ apresentou diferença na umidade em relação as cargas,

Quadro 3. Interação cargas verticais x profundidades de semeadura para a umidade da biomassa de milho (\%)

\begin{tabular}{cccc}
\hline \multirow{2}{*}{ Cargas (N) } & \multicolumn{3}{c}{ Prof. (m) } \\
\cline { 2 - 4 } & 0,03 & 0,05 & 0,07 \\
\hline 62,7 & $73,6 \mathrm{Aa}$ & $70,1 \mathrm{Bb}$ & $71,9 \mathrm{Aba}$ \\
160,7 & $72,0 \mathrm{Aa}$ & $70,4 \mathrm{Ab}$ & $72,8 \mathrm{Aa}$ \\
258,7 & $73,3 \mathrm{Aa}$ & $72,3 \mathrm{Aab}$ & $72,9 \mathrm{Aa}$ \\
356,7 & $72,6 \mathrm{ABa}$ & $74,4 \mathrm{Aa}$ & $70,2 \mathrm{Ba}$ \\
\hline
\end{tabular}

Médias seguidas de mesma letra maiúsculas nas linhas e minúsculas nas colunas não diferem entre si pelo teste de Tukey a $5 \%$ de probabilidade. 
sendo a maior umidade encontrada nas maiores cargas, provavelmente devido ao melhor contato proporcionado pela carga vertical, diminuindo os macroporos e aumentando os microporos.

Em relação às cargas dentro das profundidades observa-se que apenas a menor e maior carga apresentaram diferenças para a umidade da biomassa de milho (Quadro 3). Assim, na carga de $62,7 \mathrm{~N}$ a profundidade $0,03 \mathrm{~m}$ diferiu da profundidade $0,05 \mathrm{~m}$, sendo maior na menor profundidade. $\mathrm{Na}$ carga de $356,7 \mathrm{~N}$ ocorreu diferença entre a profundidade $0,05 \mathrm{~m}$ e $0,07 \mathrm{~m}$. Esses resultados discordam de Grotta et al. (2008) que demonstraram que a interação profundidade $\mathrm{x}$ compactação não apresenta correlação, mostrando que os fatores agem independentemente na cultura do amendoim.

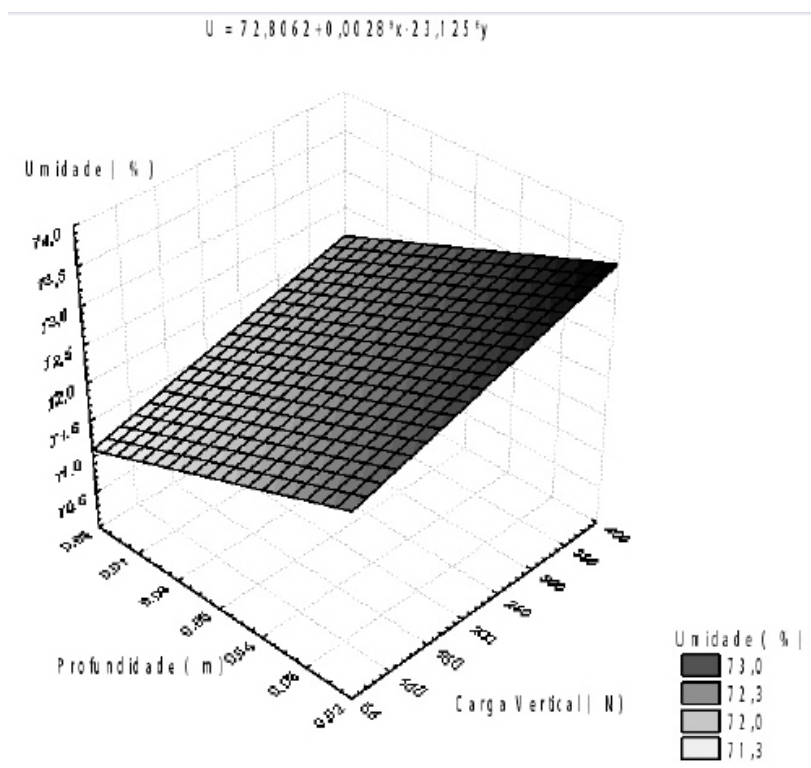

Figura 2. Superfície de resposta para a umidade da biomassa de milho em função da carga vertical e da profundidade de semeadura.

Considerando a análise de variância no Quadro 3 para a umidade da biomassa de milho verifica-se ação conjunta dos fatores. Assim, como apresentado na Figura 2, verifica-se que o modelo linear apresenta o de melhor ajuste para as cargas verticais e as profundidades de semeadura com relação a umidade da biomassa de milho. Observa-se que as maiores umidade da biomassa de milho foram encontradas nas maiores cargas e nas menores profundidades. As maiores cargas condicionam o solo a maiores quantidades de microporos (CORTEZ et al., 2006b), armazenando mais água, desta foram sugere-se que a planta de milho absorva mais água. $\mathrm{E}$ as menores umidades foram encontradas nas menores cargas e maiores profundidades. As menores cargas deixam com o solo maior número de macroporos (CORTEZ et al., 2006b) favorecendo a evaporação da água do solo, conseqüentemente a menos quantidade de água disponível.

\section{CONCLUSÕES}

- A resistência do solo à penetração é afetada pela profundidade de semeadura;

- O aumento da carga vertical proporciona aumento da resistência do solo à penetração;

- O número de dias entre a semeadura e a emergência, as produções de matéria seca e verde não respondem aos fatores cargas verticais e profundidade de semeadura;

- A umidade da biomassa de milho varia em função das cargas verticais e da profundidade de semeadura;

- O aumento das cargas verticais em menores profundidades condiciona maior umidade na biomassa de milho.

\section{REFERÊNCIAS BIBLIOGRÁFICAS}

CORTEZ, J.W.; CARVALHO FILHO, A.; SILVA, R. P. da; FURLANI, C.E.A., SIMONIS, D.B.; Comportamento da cultura do sorgo em função do tipo de rodas compactadoras e cargas verticais impostas na operação de semeadura. Engenharia Agrícola, v.26, n.2 p.461-469, 2006a.

CORTEZ, J.W.; FREDDI, O.S.; CAMARA, F.T. FURLANI, C.E.A., SILVA, R. P. da. Propriedades físicas do solo submetido a diferentes condições de semeadura e irrigação na cultura do feijão. In: CONGRESSO BRASILEIRO DE ENGENHARIA AGRÍCOLA, 35, 2006, João Pessoa. Anais... Jaboticabal: SBEA, 2006b. Cd_rom

CORTEZ, J.W.; CARVALHO FILHO, A.; SILVA, R. P. da; FURLANI, C.E.A., FREITAS, S.S. Avaliação da influência de cargas verticais sobre diferentes rodas compactadoras no ciclo de semeadura do milho. Ciência e Agrotecnologia, v.31, n.4, p.11551160, 2007. 
EDMOND, J. B.; DRAPALLA, W. J. The effects of temperature, sand and soil, and acetone on germination of okra seeds. Proceedings of the American Society for Horticultural Science, Alexandria, v.71, n.2, p.428-434, 1958.

EMBRAPA - EMPRESA BRASILEIRA DE PESQUISA AGROPECUÁRIA. Manual de analises químicas de solos, plantas e fertilizantes. Brasília: Embrapa, 1999. 370 p.

EMBRAPA - EMPRESA BRASILEIRA DE PESQUISA AGROPECUÁRIA. Sistema Brasileiro de Classificação de Solos. Rio de Janeiro: EMBRAPA/CNPSO, 2006. 306 p.

FANCELLI, A. L.; DOURADO NETO, D. Ecofisiologia e fenologia. In: FANCELLI, A. L.; DOURADO NETO, D. Produção de milho. Guaíba: Agropecuária, 2000, p. 21-54.

FORNASIERI FILHO, D. Manual da cultura do milho. Jaboticabal: Funep, 2007. 576 p.

FURLANI, C.E.A.; LOPES, A.; REZENDE, L.C.; SILVA, S.S.S; LEITE, M.A.S. Influência da compactação do solo na emergência das plântulas de milho a diferentes profundidades de semeadura. Engenharia na Agricultura, v.9, n.3, p.147-153, 2001.

GROTTA, D.C.C; FURLANI, C.E.A.; SILVA, R.P.; REIS, G.N.; CORTEZ, J.W.; ALVES, P.J. Influência da profundidade de semeadura e da compactação do solo sobre a semente na produção de amendoim. Ciência e Agrotecnologia, v.32, n.2, p.547-552, 2008.
JOHNSON, W.J.; BUCHELE, W.F. Influence of soil granule size and compaction on rate of soil drying and emergence of corn. Transactions of the ASAE, v.4, n.2, p.170-174, 1961.

Köppen, W. Climatologia: con un estudio de los climas de la tierra. Fondo de Cultura Econômica. México. 1948. 479p.

RITCHIE, S.W.; HANWAY, J.J.; BENSON, G.O. Como a planta de milho se desenvolve. Arquivo do Agrônomo, v. 15, p.1-20, 2003.

SILVA, R. P. Efeito de rodas compactadoras submetidas a cargas verticais em profundidades de semeadura nas características agronômicas do milho (Zea mays L.). 2002. 101 f. Tese (Doutorado em Agronomia) - Universidade Estadual Paulista, Jaboticabal.

SILVA, R.P.; CORA, J.E.; LOPES, A.; FURLANI, C.E.A. Ação de rodas compactadoras de semeadoras submetidas a cargas verticais na deformação do solo. Ciência e Agrotecnologia, v.29, n.4, p.839-47, 2005.

SORDI, F. Efeito da profundidade de semeadura e compactação do solo sobre a semente na cultura do feijoeiro (Phaseolus vulgaris). 2000. 50f. Monografia (Trabalho de Graduação em Agronomia) - Universidade Estadual Paulista, Jaboticabal.

VIANA, J.S.; BRUNO, R.L.A.; OILVEIRA FILHO, J.O.T.; SILVA NETO, L.F., SOUZA, C. Emergência e crescimento de plântulas de milho procedentes de sementes produzidas em sistemas de manejo de solo com e sem adubação mineral. Ciência Agronômica, Fortaleza, v.36, n.3, p. 316-321, 2005. 